\title{
Comparison of Pre-service Elementary Teachers' Mathematical Knowledge in Teaching for Length Measurement: Turkey and the United States
}

\author{
Sumeyra Dogan Coskun ${ }^{1 *}$ (D), Mine Isiksal Bostan ${ }^{2}$ (iD)
}

${ }^{1}$ Department of Elementary and Early Childhood Education, Eskisehir Osmangazi University, Eskisehir, TURKEY

${ }^{2}$ Department of Mathematics and Science Education, Middle East Technical University, Ankara, TURKEY

*Corresponding Author: s-dogan@ogu.edu.tr

Citation: Dogan Coskun, S., \& Isiksal Bostanci, M. (2022). Comparison of Pre-service Elementary Teachers' Mathematical Knowledge in Teaching for Length Measurement: Turkey and the United States. Pedagogical Research, 7(1), em0113. https://doi.org/10.29333/pr/11517

\section{ARTICLE INFO}

Received: 24 Jul. 2021

Accepted: 28 Dec. 2021

\begin{abstract}
This study investigates pre-service elementary teachers' mathematical knowledge in teaching for length measurement. More specifically, this study compares the foundation and transformation knowledge of pre-service elementary teachers from Turkey and the United States. The current study examines similarities and differences between them by applying the codes of the Knowledge Quartet model with 40 pre-service teachers selected from Turkey and the United States. This study used a test assessing pre-service teachers' mathematical knowledge in teaching about the students' mistakes, difficulties, misconceptions, the reasons for them, and their strategies to overcome them related to the topic of length measurement. The findings indicated that while US pre-service teachers had more secure foundation knowledge in identifying the possible errors, Turkish pre-service teachers showed greater foundation knowledge in identifying the possible reasons for these errors. On the other hand, the pre-service teachers in both countries have similar transformation knowledge to suggest strategies to correct students' errors. These findings might provide some insights about how pre-service teachers' mathematical knowledge may be similar or different in different countries. Furthermore, these similarities and differences might help researchers and teacher educators emphasize the importance of the quality of teacher education programs.
\end{abstract}

Keywords: pre-service elementary teachers, mathematical knowledge in teaching, length measurement

\section{INTRODUCTION}

Students' understanding and success is influenced by so many factors and teachers' effectiveness is one of these factors (Baumert et al., 2010; McGraner et al., 2011; Rothstein, 2010). Furthermore, some researchers and policy documents emphasized that teacher knowledge has important influence on classroom instruction and hence on student learning (Grossman \& McDonald, 2008; Ma, 1999; National Mathematics Advisory Panel [NMAP], 2008). Therefore, researchers and policymakers have focused a great deal of time and attention on teacher education and teacher knowledge.

The definition, sub-categories, and name of teacher knowledge are not the same in all countries, but in a time of globalization, researchers around the world agree that mathematical knowledge in teaching is important to improve the students' understanding of mathematics (Ball et al., 2008; Rowland et al., 2003, 2005; Shulman, 1986, 1987). However, there are limited international comparative studies investigating teachers' mathematical knowledge in teaching (Cai, 2005; Huang, 2014; Huang \& Cai, 2011; Huang \& Li, 2014; Ma, 1999). Investigating teachers' mathematical knowledge in teaching from different countries can be important. First of all, a comparison of pre-service elementary teachers' mathematical knowledge in teaching can contribute to an understanding of their knowledge in each country. Furthermore, examining their knowledge in different countries would be beneficial to understand teacher knowledge from a broader perspective and this would also give valuable information for policy makers to see the effectiveness of their education programs. By this way, we could compare the outputs of the programs in different cultures. That is, even the aim of teacher education programs is to raise qualified teachers, and how their knowledge differ could be examined and compared in cross cultural studies. In this study, it is aimed to examine Turkish and US pre-service elementary teachers' mathematical knowledge in teaching for the topic of length measurement. Then, the second aim is to examine the extent of the differences if exist between Turkish and US pre-service elementary teachers' mathematical knowledge in teaching. 


\section{Mathematical Knowledge in Teaching}

Early on, researchers tried to understand teacher knowledge by describing and defining what teacher knowledge and its components are (Ball et al., 2008; Rowland et al., 2003, 2005; Shulman, 1986). Subject matter knowledge and pedagogical content knowledge proposed by Shulman (1986) are universally accepted as the utmost important components of teacher knowledge. While the subject matter knowledge was defined as "beyond knowledge of facts or concepts of a domain" (Shulman, 1986, p. 9), the pedagogical content knowledge was defined as "the blending of content and pedagogy into an understanding of how particular topics, problems or issues are organized, represented, and adapted to the diverse interests and abilities of learners, and presented for instruction" (Shulman, 1987, p. 4).

While many researchers used his framework to investigate teacher knowledge, some other researchers proposed new frameworks to ensure better assessment of teachers' mathematical knowledge in teaching by expanding his framework (Ball et al., 2008; Rowland et al., 2003, 2005). For instance, Ball et al. (2008) stated that Shulman's (1986) model did not give a clear distinction between subject matter knowledge and pedagogical content knowledge of teachers and a specific framework related to teacher's knowledge for mathematics was needed. In fact, Ball et al. (2008) criticized by saying:

...nearly one-third of the articles that cite pedagogical content knowledge do so without direct attention to a specific content area - the very emphasis of the notion - instead making general claims about teacher knowledge, teacher education, or policy (p. 3).

Therefore, Ball et al. (2008) developed a model, Mathematics Knowledge for Teaching, to examine the mathematical knowledge specific to teachers. Specifically, the difference between subject matter knowledge and pedagogical content knowledge of teachers is highlighted in their model. Davis and Renert (2013) assert that categorizing teacher knowledge may be a starting point; however, it should be noted that teacher knowledge is too complex to be compressed between categories.

To move away from the dichotomy of subject matter versus pedagogical content knowledge, Rowland et al. (2003) developed a model: Knowledge Quartet. Since their model does not emphasize the differences between subject matter knowledge and pedagogical content knowledge of teachers, they used a new term for the combination of these two terms, which is, mathematical knowledge in teaching. To examine teacher knowledge, The Knowledge Quartet model uses the following dimensions: foundation, transformation, connection, and contingency. Foundation includes teachers' knowledge about possible errors, misconceptions, mathematical terminology, etc., and affects the other three dimensions. Transformation is related to how teachers transform their own knowledge by means of demonstrations, examples, and representations to make it accessible to students. Connection relates to possible connections among the topics of mathematics and order of examples or tasks throughout instruction. The last dimension, Contingency, refers to teachers' ability to respond to unexpected moments by thinking "on their feet" (Rowland et al., 2009, p. 135). By means of the dimensions, teacher educators and mentor teachers analyze pre-service teachers' mathematical knowledge in teaching and help pre-service teachers see which parts of their knowledge should be improved.

The focus of this study is mathematical knowledge in teaching indicated through the foundation and transformation dimensions. The reason for this focus is that although it is known that students in different countries have similar errors and difficulties for the topic of length measurement, whether pre-service teachers in different countries have the same ability to identify these errors and difficulties, or suggest the same strategies to overcome them is as yet unknown. In this context, this study aims to examine the parts that differ in Turkey's and the United States' pre-service elementary teachers' mathematical knowledge in teaching associated with foundation and transformation for the topic of length measurement.

\section{Difficulties Related to Length Measurement}

While students explore and try to make sense of their world, they encounter measurement concepts and ask questions related to measurement concepts (Copley, 2000). For example, "how much, how big, how far, how tall, how short, how many" are some of the questions that are asked many times in a day (Martinez, 2007, p. 199). Therefore, the measurement strand is included in elementary mathematics curriculum of various countries including Turkey and the United States (Chen et al., 2009; Clements \& Sarama, 2007; Ministry of National Education [MoNE], 2015; National Council of Teachers of Mathematics [NCTM], 2000; Outhred \& Mitchelmore, 2000) and it is introduced in the first grade and then extended throughout elementary school in Turkey and the United States (MoNE, 2015; NCTM, 2000).

Although students are engaged in measurement activities from the first grade forward, they have some difficulties that resulted in lower scores in international tests such as the Trends in International Mathematics and Science Study (TIMSS) and the Programme for International Student Assessment [PISA] (Educational Research and Development Department [EARGED], 2003). Length is the first measurable attribute and is one of the attributes in which students have difficulties. Since the length measurement topic is the base for the other measurement content strand topics, students' difficulties in this topic are important (Cullen \& Barrett, 2010). Knowing this, it would not be surprising that students who have difficulties in the topic of length measurement would also have difficulties in perimeter, area measurement, or volume measurement.

Previous extensive studies have revealed that students have difficulties in understanding and applying the length measurement concept. One of the most common difficulties of students is to leave gaps between the units or iterate the units with overlaps (Lehrer, 2003). In the same way, Barrett and Clements (2003) emphasize that students do not comprehend the importance of iterating the unit without leaving or overlapping along the object. Therefore, they cannot measure if the number of the unit is not sufficient to fully cover the length of an object (Bragg \& Outhred, 2004). If the chosen unit does not fully cover the length of an object or if it gets longer when one more of the chosen unit is added, students, then, think that they have to change the unit that they chose (Sarama et al., 2021). Furthermore, since they do not know how the iteration process is related to the 
number as a measurement, they can use different-sized units together to measure a length (Clements \& Sarama 2009; Lehrer et al., 2003). The important thing for students is that the length must be filled out with units whose sizes may be different or equal (Sarama et al., 2021). That is, the students have difficulties in discovering the inverse relationship between the unit size and the number of units to measure a length. As a result, they have difficulties in understanding that the line segments between two consecutive benchmarks of a ruler must be equal in length (Lehrer, 2003). Furthermore, failing to use the same-sized units results in students counting benchmarks on the ruler instead of counting the line segments between two consecutive benchmarks (Bragg \& Outhred, 2004) and just focusing on the end of the ruler to read the resulting number (Kamii, 2006; Smith et al., 2013). In other words, students think that just focusing on or reading off the numerals on the ruler is enough to correctly measure the length. Not only that, but, when these students were asked to state the length of an object, they just state the numerals without including the units (e.g. five instead of five cm) (Sarama et al., 2021). Smith et al. (2013) attributes the reason for this difficulty to not understanding the structure of the ruler. Another difficulty of students related to counting is to start counting from the benchmark for 1 on the ruler (Lehrer, 2003). Drake (2014) explains the reason for this difficulty as counting starts at 1 , students prefer to align the object at 1 rather than 0 . If these students also count benchmarks rather than line segments separating the benchmarks, they will find an answer which is one more than the correct answer. Moreover, some of the students cannot read the ruler correctly when the object is not aligned at the 0 benchmark (Kloosterman et al., 2009). That is, if the students align one end of the object on the 0 benchmark, they can find the length of an object by means of looking to the right end of the object.

Clements and Stephan (2004) explain the reason for students' difficulties is that "measurement should not be taught as a simple skill. It is a complex combination of concepts and skills that develops slowly over years" (p. 307-308). Because of this, the measurement instruction must be different from instruction in which teachers present a topic through telling and demonstrating necessary procedures, ask students to practice the shown procedures, and just provide yes/no answers to students' questions (Kilpatrick et al., 2001). In the same way, Ball and Forzani (2011) assert that "improving educational outcomes for young people depends on developing and supplying skilled instructional practices" (p. 17). Furthermore, students' understanding of mathematics during these early years is important, as "the foundation for children's mathematical development is established in the earliest years" (NCTM, 2000, p. 73). Therefore, teachers need to adapt their instruction "to move toward mathematical goals, capture and sustain interest, and engage students in building mathematical understanding" (NCTM, 2000, p. 18) so that students can find mathematics interesting and engaging and carry their enthusiasm for mathematics throughout their future education lives.

To validly and reliably measure students' success, compare students' success with other ones around the world, and take necessary precautions according to results, governments participate in large-scale tests like TIMSS. In TIMSS, while a country having a score of 500 and above is accepted as a high performing country, a country having a score lower than 500 is accepted as a low performing country. The United States and Turkey, the countries selected for this study, is a high and a low performing country, respectively. Specifically, average mathematics scores of students in Turkey were lower than those of in the United States in TIMSS 2003, 2007, 2011, and 2015. This difference may be attributed to different reasons and one of these reasons is teachers' performance. To be more specific, the Organization for Economic Cooperation and Development (OECD) (2005) explains that improving teacher performance would positively affect students' success in these tests. All in all, to be able to succeed in this, teachers need to provide a high quality instruction, which is dependent on teachers' mathematical knowledge in teaching (Grossman et al., 2011).

It is accepted that teachers' beliefs and hence their mathematical knowledge in teaching, no matter how small, are affected by their cultures, but there is no study that has specifically compared the mathematical knowledge in teaching of pre-service elementary teachers from Turkey and the United States. To gain an insight into underlying reasons why Turkey is a low performing country or the United States is a high performing country, we focused on pre-service elementary teachers' mathematical knowledge in teaching about possible difficulties related to the topic of length measurement, the reasons for them, as well as their strategies to handle these difficulties. In this context, this study tries to answer the following questions:

1. What is the nature of Turkish and US pre-service elementary teachers' mathematical knowledge in teaching associated with the foundation and transformation dimensions for the topic of length measurement?

2. To what extent is pre-service elementary teachers' mathematical knowledge in teaching associated with the foundation and transformation dimensions differ between Turkey and the United States for the topic of length measurement?

\section{METHODOLOGY}

\section{Participants}

To investigate Turkish and the US pre-service elementary teachers' mathematical knowledge in teaching considering foundation and transformation for length measurement, a cross-sectional survey design was used. In the cross-sectional survey designs, the data were collected at one point in time from a predetermined sample (Frankel \& Wallen, 2006) and participants' "current attitudes, beliefs, opinions, or practices" were examined (Creswell, 2012, p. 377). Creswell (2012) also emphasizes that since it may not be possible or practical to use probability sampling, it may be required to select individuals who are convenient. For this purpose, the convenience sampling method was used to obtain a sample of this study. Participants were drawn from volunteers who were undergraduate pre-service teachers from a university in the middle part of Turkey and two universities in the Midwestern part of the United States. The university in Turkey was of particular interest to the first author, given where she worked. Furthermore, the universities in the United States were selected as they were the only ones having an elementary teacher education program in the city where the first author worked as a visiting scholar. Since having some basic information about the 
Table 1. Questions and dimensions

\begin{tabular}{lll}
\hline Question & Dimension(s) of KQ & Code(s) of KQ \\
\hline 1 & Foundation & Overt subject knowledge \\
\hline $2 a$ & Foundation & Overt subject knowledge \\
\hline $2 b$ & Foundation & Identifying errors \\
\hline $2 c$ & Foundation & Identifying errors \\
\hline $2 d$ & Transformation & Choice of examples, choice of representation, and demonstration \\
\hline $3 a$ & Foundation & Identifying errors \\
\hline $3 b$ & Foundation & Identifying errors \\
\hline $3 c$ & Transformation & Choice of examples, choice of representation, and demonstration \\
\hline $4 a$ & Foundation & Overt subject knowledge \\
\hline $4 b$ & Foundation & Identifying errors \\
\hline $4 c$ & Foundation & Identifying errors \\
\hline $4 d$ & Transformation & Choice of examples, choice of representation, and demonstration \\
\hline
\end{tabular}

elementary teacher education programs offered by these universities might help us to interpret the findings better, brief information about these programs was also provided.

In Turkey, pre-service teachers have to finish a four-year program and follow nearly the same coursework which is determined by the Higher Education Council. During this four-year program, the pre-service teachers are required to take subject matter, general education, and elective courses. One of the subject matter courses, Mathematics at Elementary School, is taken by preservice teachers in their first semester. This course introduces them to fundamental elementary mathematical concepts like numbers, number systems, arithmetical operations, measurement, geometry, etc. In addition to this course, pre-service teachers also take Teaching of Elementary Mathematics I and II courses in the third year of the program. In these courses, pre-service teachers learn instructional methods and strategies that can be used to teach the concepts in real classrooms.

Pre-service teachers in the United States also have to finish a four-year program which includes subject matter, general education, and elective courses. However, contrary to Turkey, coursework that pre-service teachers have to follow is determined by each state. Furthermore, the participant pre-service teachers in the USA take two courses called Mathematics for Elementary Teachers I and Mathematics for Elementary Teachers II in the first year of their programs. The contents of these courses are nearly similar to the ones in Turkey as these courses provide pre-service teachers with conceptual understanding of natural numbers, number systems, operations, geometry, and measurement. The participant pre-service teachers take only one method course, Teaching and Learning Elementary School Mathematics, which includes information about how the topics should be taught by means of materials so that students learn mathematics conceptually. As can be seen from above, although the number of the courses that pre-service teachers enrolled in are different in Turkey and the United States, the content of these courses are very similar. The pre-service teachers who constituted the sample of this study were also registered for the elementary mathematics teaching course which is Teaching of Elementary Mathematics II in Turkey and Teaching and Learning Elementary School Mathematics in the USA. In the end, the sample consisted of 20 Turkish and 20 US pre-service elementary teachers who agreed to complete the Mathematical Knowledge in Teaching Test for Length Measurement.

\section{Data Collection and Analysis}

The questions in the Mathematical Knowledge in Teaching for Length Measurement Test were prepared according to the foundation and transformation dimensions of the Knowledge Quartet model (Rowland et al., 2005). Specifically, the focus of the test was pre-service elementary teachers' mathematical knowledge in teaching about the students' mistakes, difficulties, and misconceptions related to length measurement, the reasons for them, and their strategies to overcome these troubles. That is, the test asked more than foundation knowledge so that the pre-service teachers had to think about their transformation knowledge related to the topic of length measurement. This test consisted of four open-ended structured questions with subquestions and was administered to the pre-service elementary teachers in Turkey and the United States. To indicate which dimension each question and sub-question was related to, Table 1 was created.

Before administering the test to US pre-service teachers, the questions in the test were translated from Turkish to English by the authors. The translation was also checked and corrected by a native English-speaking mathematics education professor. For the data collection, the test was distributed to all pre-service teachers who volunteered during the elementary mathematics teaching course, and the pre-service teachers finished and returned the test to the first author during the course hour. Prior to this process, the first author explained the purpose of the research and ensured that the data would be kept confidential to the preservice teachers. Since the questions in the test were open-ended, the pre-service elementary teachers' responses to each question were analyzed both quantitatively and qualitatively. Specifically, to examine the nature of Turkish and US pre-service elementary teachers' mathematical knowledge in teaching associated with the foundation and transformation dimensions for the topic of length measurement, the pre-service teachers' responses were analyzed qualitatively. To answer the question of to what extent is pre-service elementary teachers' mathematical knowledge in teaching associated with the foundation and transformation dimensions differ between Turkey and the United States for the topic of length measurement, the pre-service teachers' responses were analyzed quantitatively. Throughout these processes, to look for similarities and differences in Turkish and US pre-service teachers' foundation and transformation knowledge, their responses to the questions were analyzed by putting the similar solutions and strategies together. These responses were also reported as a frequency to present the amount of similarities and differences between Turkish and US pre-service teachers' responses and direct quotations from the pre-service teachers' responses were provided where appropriate. 


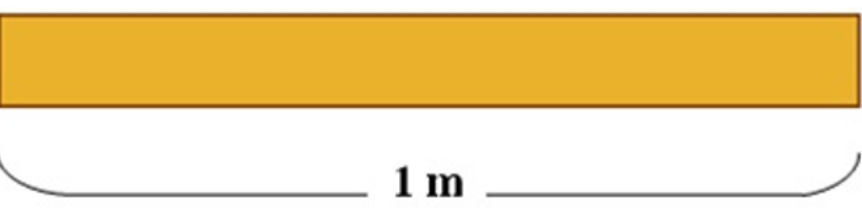

Figure 1. Wooden ruler (1m)

\section{FINDINGS}

The aim of this study is to examine the similarities and differences in Turkish and US pre-service teachers' mathematical knowledge in teaching associated with foundation and transformation for length measurement. For the first question, the preservice elementary teachers were asked to explain the measurement concept in their own words considering the measurement content strand of the mathematics curriculum. In the USA, 3 of 20 pre-service elementary teachers explained the measurement concept similar to the literature by stating "assigning a numerical value to an attribute of an object" or "quantifying something so that it can be compared to other things in its category." Similarly, the measurement concept was also explained as in the literature by seven Turkish pre-service elementary teachers. Specifically, some of these pre-service teachers mentioned that "measurement is a process of determining a number representing a particular attribute of an object." Half of the pre-service teachers in Turkey tried to explain the measurement concept by giving examples like a board's length, a box's weight, a classroom's perimeter, a rug's area, etc. Contrary to providing examples, most of the US pre-service teachers (12 of 20) stated that measurement provides how tall, wide, high, heavy, big, etc. an object is. Furthermore, some pre-service teachers from the US stated that measurement is a mathematics topic which includes the most commonly encountered concepts of daily life. In both Turkey and the US, there were also pre-service teachers who could not explain what measurement is.

In the second question, a tailor tries to measure a piece fabric using a $1 \mathrm{~m}$ wooden ruler whose benchmarks are not marked on the ruler, as shown on Figure 1.

The pre-service elementary teachers were asked to determine whether or not the tailor can measure out a $125 \mathrm{~cm}$ fabric by means of this ruler. The pre-service teachers' answers for this question did not differ between the two countries. Specifically, of the 20 pre-service teachers, 16 US and 17 Turkish pre-service teachers correctly answered this question. Specifically, these preservice teachers explained that since there are 25 centimeters in a quarter of a meter, the tailor can measure by folding the fabric in half two times. Four incorrect answers given by US pre-service teachers for this question were related to the length or benchmarks of the ruler. Two pre-service teachers whose explanations related to the length of the ruler stated that since the length of the ruler is shorter than the length of the fabric, the $125 \mathrm{~cm}$ fabric cannot be measured. The remaining two pre-service teachers explained that since the benchmarks are not given on the ruler, the tailor cannot measure the fabric. This explanation was similar to the explanations provided by three Turkish pre-service teachers who could not provide correct answers for the question. Specifically, these three teachers explained that since there are not any benchmarks on the ruler, the tailor cannot know the exact place of $25 \mathrm{~cm}$ and hence cannot measure out a $125 \mathrm{~cm}$ fabric.

Another sub-question of the second question was related to possible errors of students while using this wooden ruler. Most US pre-service elementary teachers (12 of 20) mentioned that the students may not make the conversion between a meter and centimeter correctly. In the same way, 11 Turkish pre-service teachers stated that since the students may not know the meter to centimeter conversion, they may not measure the fabric correctly. Not correctly marking the benchmark for $25 \mathrm{~cm}$ on the ruler was also mentioned by two US pre-service teachers and five Turkish pre-service teachers as a student error. Furthermore, teachers in both countries explained that although students know that there are 100 centimeters in a meter, they may not notice that $25 \mathrm{~cm}$ is a quarter of a meter and not know how to use this relationship to mark the benchmark for $25 \mathrm{~cm}$. The remaining Turkish preservice teachers (4 of 20) stated that another student error might come from just trying to cut the fabric approximately. Other possible student errors mentioned by US pre-service teachers were accepting the ruler as $1 \mathrm{~cm}$ instead of $1 \mathrm{~m}$ and trying to use it for 125 times, accepting the ruler as $125 \mathrm{~cm}$ and trying to use it just once, and thinking that the fabric cannot be measured using this ruler as there is not enough ruler to lay down along the length of the fabric.

When the reasons for these possible errors were asked, nearly all US pre-service teachers attributed the basic reason to poor length measurement instruction. They stated that students may not have learned how to make a conversion between a meter and centimeter. Specifically, two pre-service teachers explained that since teachers may not have explained there are 100 centimeters in a meter, the student may not have fully understood meter to centimeter conversion factor is 100 . Similarly, one of the preservice teachers in the United States explained that since students may not have comprehended the reasoning behind conversion rules between different length measurement units, they may not have memorized these rules and as a result, may not have converted the length from one unit to another. In the same way, seven Turkish pre-service teachers stated that students may not have learned how to make a conversion between a meter and centimeter. The other seven Turkish pre-service teachers attributed the cause of these reasons to length measurement instruction by stating that students may not have been provided enough examples throughout the instruction. One other example of the cause of these errors, as was stated by a Turkish pre-service teacher, since this kind of ruler is not used in daily life, the students may not know how to use it.

The final sub-question of the second question asked the pre-service teachers to suggest teaching methods, strategies, and materials to overcome these errors. Most of the US pre-service teachers ( 16 of 20 ) suggested that bringing a ruler to classroom and 


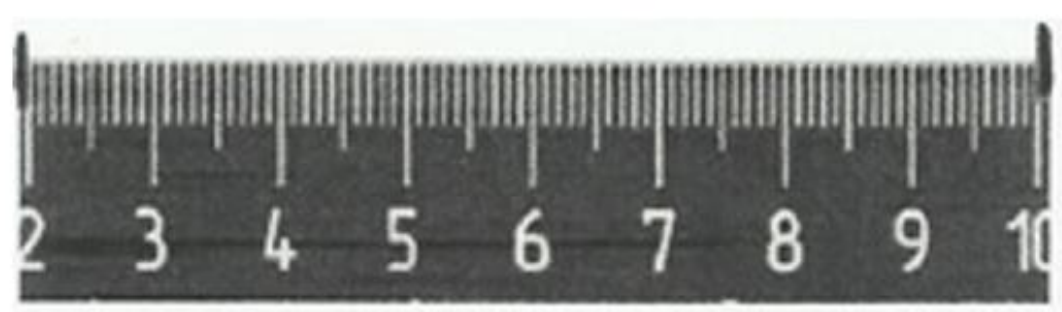

Figure 2. Broken ruler

physically showing how many centimeters there are in a meter is an effective way to help students understand conversion rules conceptually. Furthermore, one of US pre-service teachers explained that using different rulers, such as $30 \mathrm{~cm}$ in length or $20 \mathrm{~cm}$ in length, can be helpful to show length of an object would be the same regardless of the ruler's length. Similar to this suggestion, Turkish pre-service teachers explained that having students design their own rulers may enable them to notice their errors. Other strategies suggested by Turkish pre-service teachers to overcome these errors were re-teaching the topic, solving enough conversion examples, and making students familiar with these kinds of rulers. In addition to practicing enough examples before letting students solve conversion examples on their own, two US pre-service teachers stated that distributing a conversion rule sheet may be useful when students could not remember the rules.

In the third question, the pre-service elementary teachers were given the following dialogue:

Teacher: Can you measure the class's length using a $1 \mathrm{~m}$ ruler?

Jack: No, I cannot.

Teacher: Why?

Jack: My ruler's length is not enough to measure it.

They were then asked about Jack's error. Twelve of US pre-service teachers explained that since the length of Jack's ruler is shorter than the length of the class, Jack may have thought that he needs longer measurement tools. Similar to this explanation, in Turkey, more than half of the pre-service teachers (13 of 20) explained that Jack may have thought that he can only measure the objects that are shorter than one meter. The remaining US pre-service teachers (8 of 20) stated that since Jack thinks that he can only use the ruler once, he might have provided such an explanation. In the same way, other Turkish pre-service teachers ( 7 of 20) concluded that Jack may have thought that the length of one ruler is not enough to measure the class's length as he did not consider using the ruler more than once.

When the reasons for Jack's error were asked, 14 of US pre-service teachers explained that Jack may not know that a ruler can be used several times to measure the length of a longer object. Other pre-service teachers in the United States (6 of 20) stated that since Jack may not have used $1 \mathrm{~m}$ ruler before, he may not know how to use it. Similar to this statement, 12 Turkish pre-service teachers explained that since the teacher could not have provided Jack with measurement activities in which he measured the lengths of objects longer than a meter, he may not know what to do. While three Turkish pre-service teachers attributed Jack's thinking to not comprehending the meaning of length concept, five Turkish pre-service teachers could not suggest any possible reasons for Jack's error.

In the final sub-question, the pre-service teachers were also asked about how they would explain to Jack that his thinking is not correct. All US pre-service teachers stated that they would tell Jack that a ruler can be used more than once. Four of these teachers specifically used the term iteration. In fact, one of the pre-service teacher described this process as the following:

I would tell him that he can iterate the ruler. He can use the ruler and mark the ending point, and use the ruler again by starting from the point marked. Then, he can repeat these steps until he reaches the ending point of the class.

Similar to US pre-service teachers, more than half of Turkish pre-service teachers' explanations (16 of 20) were related to using the ruler more than once. Many of these teachers described how they would tell Jack that he is not supposed to use the ruler once; instead, he can use it repeatedly along the length of the class. The remaining four Turkish pre-service teachers explained that they would physically show how a ruler can be used to measure an object whose length is longer than that of the ruler.

In the fourth question of the test, pre-service teachers were asked to find the length of a broken ruler piece which was a part of $30 \mathrm{~cm}$ ruler as shown in Figure 2.

Of the 15 US pre-service elementary teachers who answered the question correctly, 12 of them provided details about their thinking. Specifically, while eight pre-service teachers subtracted $2 \mathrm{~cm}$ from $10 \mathrm{~cm}$, four pre-service teachers counted the spaces between two consecutive benchmarks on the ruler to find $8 \mathrm{~cm}$. On the other hand, the remaining three pre-service teachers just wrote $8 \mathrm{~cm}$, without showing any details of their solutions. Similarly, of the 17 Turkish pre-service teachers who answered correctly, most of them (13 of 17 ) found $8 \mathrm{~cm}$ by subtracting $2 \mathrm{~cm}$ from $10 \mathrm{~cm}$. Two of the 17 pre-service teachers showed similar solutions by counting the spaces between two consecutive benchmarks, such as 2-3, 3-4, .., 9-10. The remaining of the 17 pre-service teachers mentioned that if they accept the benchmark for 2 of the broken ruler as a benchmark for 0 of the whole ruler, it would continue to 8 . Therefore, the length of this broken ruler would be $8 \mathrm{~cm}$ as shown in Figure 3 . 


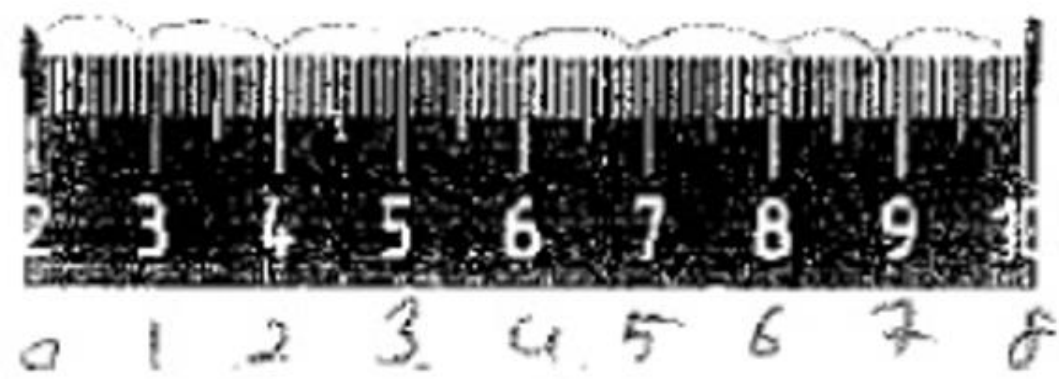

Figure 3. Length of the broken ruler

Although it was mentioned that the ruler was a part of $30 \mathrm{~cm}$ ruler, four US pre-service elementary teachers wrote the answer as 8 inches. Furthermore, one pre-service teacher stated that since the only ruler part missing is between $1 \mathrm{~cm}$ and $2 \mathrm{~cm}$, the length of this broken ruler is $9 \mathrm{~cm}$. In Turkey, similar to this pre-service teacher's statement, three pre-service teachers explained that since only the part between $1 \mathrm{~cm}$ and $2 \mathrm{~cm}$ is missing, the length of this broken ruler is $9 \mathrm{~cm}$.

For the first sub-question of the fourth question, the pre-service teachers were asked to explain how a student may have found the length of this broken ruler piece as $9 \mathrm{~cm}$. In the United States, 11 pre-service teachers expressed that the student may have counted the benchmarks on the ruler instead of the spaces between the consecutive benchmarks. Specifically, one of these preservice teachers explained in the below:

The student has to count 2-3, 3-4, 4-5, .., 9-10 to correctly find the length of it. However, if the student counted the numbers like $2,3,4,5,6,7,8,9,10$, the student could have found the answer as $9 \mathrm{~cm}$, which is wrong.

In Turkey, similarly, seven pre-service teachers explained that the student may have counted the numbers or the benchmarks and hence they found its length as $9 \mathrm{~cm}$. Furthermore, five and 10 pre-service teachers, in the United States and Turkey, respectively, stated that since the student may have accepted that a ruler starts from $1 \mathrm{~cm}$ instead of $0 \mathrm{~cm}$, they may have found the length of this broken ruler as $9 \mathrm{~cm}$ by subtracting $1 \mathrm{~cm}$ from $10 \mathrm{~cm}$. Other similar explanations provided by three US pre-service teachers were related to the benchmark for 0 of rulers. These pre-service teachers, specifically, emphasized that since some students forget to align their rulers to the benchmark for 0 , the student in the question, similar to these students, may have aligned the broken ruler to the benchmark for 1 rather than the benchmark for 0 and found the length of this broken ruler is $9 \mathrm{~cm}$. Contrary to the pre-service teachers who explained how the student may have found the length of the broken ruler as $9 \mathrm{~cm}$ or why the student's answer was wrong, there were also the pre-service teachers who accepted the student's answer as correct. Actually, these were the one US and three Turkish pre-service teachers who found the broken ruler's length as $9 \mathrm{~cm}$ in the first sub-question mentioned above.

In the next sub-question, pre-service teachers were asked to explain possible reasons for these errors, and, specifically, this student's error. Both US and Turkish pre-service teachers' explanations were similar as they listed nearly the same reasons. These reasons were not being familiar with a broken ruler, starting to count from benchmark for 1 , counting the benchmarks rather than the distances between two consecutive benchmarks, and not comprehending the meaning of length measurement concept.

Although the pre-service teachers in both countries listed similar reasons for the student's error, there were differences in their strategies to overcome the error, which was the last sub-question. Starting with the similar ones, seven US and nine Turkish preservice teachers emphasized that bringing such kind of a ruler to the classroom, letting students use the ruler, and encouraging them to compare their measurements would be beneficial. In the United States, while five pre-service teachers preferred to emphasize starting and ending points of rulers, four pre-service teachers preferred to emphasize spaces not benchmarks on rulers to overcome these errors. One of the four pre-service teachers described as in the following:

I would draw a number line and would make my students count the skips.

Another one described their strategy that:

I would use objects to help them see that there are $8 \mathrm{~cm}$ there. I would put one button in each space to indicate the $\mathrm{cm}$ of the ruler.

Contrary to these emphases, seven Turkish pre-service teachers asserted that re-teaching and re-explaining the meaning of length concept can help students who have difficulties in length measurement. For instance, one of these pre-service teachers explained it by giving the example below:

When we would like to measure an object's length by our span, although we use our two fingers, we cannot say two spans. We have to say one span. So this is similar to the ruler. We have to consider the distance between two consecutive numbers. 


\section{DISCUSSION, CONCLUSIONS, AND SUGGESTIONS}

This study aimed to compare the pre-service elementary teachers' mathematical knowledge in teaching associated with foundation and transformation in Turkey and the United States for the topic of length measurement by identifying the similarities and differences in their responses to the questions. It was found that the explanations for the measurement concept provided by the pre-service teachers did not differ much between the United States and Turkey. Specifically, 3 US and 7 Turkish pre-service teachers described the measurement concept similar to Clements and Stephan's (2001) definition of measurement which was defined as "assigning a number to continuous quantities" (p. 3) and that of Bright (1976 as cited in Zembat, 2007, p. 205) was defined as "process of a comparison of the object/situation/event being measured and the same attribute of a given unit of measure." Considering their explanations, it can be concluded that these pre-service teachers' foundation knowledge is adequate, as they comprehended that measurement includes both identifying an attribute and quantifying the identified attribute.

The results on the first sub-question of the second question showed that there were similarities in the explanations of both US and Turkish pre-service teachers whose answers were correct. These pre-service teachers reached the correct answer by making connections to the topic of fractions. However, the result of this sub-question showed some weakness in the pre-service teachers' mathematical knowledge in teaching associated with foundation in both countries for length measurement. To be more specific, these teachers stated that it is not possible to measure out the fabric with a ruler without any benchmarks on it. Wilson and Rowland (1993) emphasize that students have difficulties in measuring length of an object with a ruler that has no numbers on it. Since the pre-service teachers' statements were similar to this emphasis, it can be concluded that these teachers also have difficulties in length measurement. Another student difficulty arises when the length of a ruler is not enough to cover the length of an object to be measured (Bragg \& Outhred, 2004; Sarama et al., 2021). A similar finding was disappointingly found in this study as one US pre-service teacher mentioned that the ruler is not long enough to measure the fabric. An additional common error related to length measurement is zero point of ruler. Students fail to measure an object's length correctly if it does not start from zero point (Drake, 2014; Kloosterman et al., 2009; Lehrer, 2003; Wilson \& Rowland, 1993). Similar to these students, some of the pre-service teachers in both countries had difficulty in correctly finding the length of broken ruler. The reason for this difficulty may have resulted from the pre-service teachers not conceptually knowing what is being counted on the ruler. As a result, these pre-service teachers may not have discovered that the benchmarks or numbers on this broken ruler do not represent the result of iterating $9 \mathrm{~cm}$-sized units. In the same way, they may not have discovered that the length of the broken ruler is equal to the distance between the beginning benchmark ( 2 in this ruler) and the end benchmark ( 10 in this ruler).

Contrary to these similarities, there were differences in US and Turkish pre-service teachers' responses for the next subquestions. While US pre-service teachers had more secure foundation knowledge in identifying the possible errors resulted from using a ruler without benchmarks, Turkish pre-service teachers showed greater foundation knowledge in identifying the possible reasons for these errors. Stephan and Clements (2003) assert that students who could not comprehend partitioning, one of the important components of the length measurement, focus on the benchmarks rather than the difference between the benchmarks. However, the pre-service teachers who could identify the reasons did not attribute the student's difficulty to this component. Moreover, some of the Turkish pre-service teachers could not identify possible reasons behind the student's (Jack in the question) error which was related to the iterating, another important component of length measurement. Researchers emphasize that teachers need to know reasons for errors rather than simply identifying them (Ball et al., 2008; Rowland et al., 2003, 2005) to use them as learning opportunities to improve students' understanding (Borasi, 1996). Since the pre-service teachers from each country were more successful in one of the two aspects, they might have difficulties in turning these moments into opportunities. One of the reasons behind this difference may be the content of the method courses in which these pre-service teachers enrolled. Specifically, teacher educators in the United States might emphasize what kind of errors or misconceptions students have, but in contrast, teacher educators in Turkey might highlight possible reasons for students' difficulties.

Furthermore, teachers need to know what kind of strategies, examples, or representations would be helpful, as well as why and when they are helpful to address and overcome students' errors which are strictly related to their transformation knowledge (Ball et al., 2008; Rowland et al., 2003, 2005; Shulman, 1986). However, the typical strategies that the pre-service teachers in this study offered to overcome or correct the errors were re-explaining the topic or re-teaching by models. There were also the preservice teachers in both countries who could not suggest or did not explain their strategies to handle these errors. This finding is important as these pre-service teachers are the ones who could not identify the error made in the question. That is, pre-service teachers' foundation knowledge might affect their transformation knowledge, which is consistent with the related literature (Rowland et al., 2009). There is no doubt that to be able to suggest strategies, the first thing that is a must is to identify errors as it will be used "as a route into understanding learner thinking" (Brodie, 2014, p. 222). Therefore, it can be concluded that since these pre-service teachers could not identify the errors, they could not use them as a route. Ball and Bass (2003) explain that participating in professional development programs that focus on the mathematical reasons for these errors rather than students' abilities may help pre-service teachers effectively deal with them. Therefore, teacher educators can include such kind of activities in which pre-service teachers collectively try to identify both errors and reasons for them into their courses, and then suggest strategies to deal with them.

To sum up, contrary to the minor differences, the pre-service elementary teachers in both the United States and Turkey have similar foundation and transformation knowledge. Therefore, it can be concluded that just as students in different countries have similar errors, pre-service teachers in different countries have similar foundation knowledge to identify these errors and their potential reasons, and transformation knowledge to suggest strategies to correct them. The reason for these similarities in the nature of Turkish and US pre-service elementary teachers' mathematical knowledge in teaching was not investigated in this study which can be accepted as the limitation of this study. The results of this study based on the pre-service teachers' responses on the 
Mathematical Knowledge in Teaching for Length Measurement Test rather than on the courses that they enrolled. However, the contents of the courses taken by the pre-service teachers were so similar. In other words, one possible explanation for these similarities in their knowledge, therefore, might be attributed to these courses. Since the pre-service teachers in this study may not enough represent the general situation of the pre-service teachers' foundation and transformation knowledge in Turkey and the United States, further research can be conducted with a larger sample of pre-service teachers from different parts of the countries. Further studies can investigate whether pre-service teachers' mathematical knowledge is affected by courses whose contents are different. Furthermore, it was only focused on the pre-service teachers' foundation and transformation knowledge of length measurement. Pre-service teachers' mathematical knowledge in teaching associated with foundation and transformation for the other topics might be investigated.

Author contributions: All authors have sufficiently contributed to the study, and agreed with the results and conclusions.

Funding: This study is funded by The Scientific and Technological Research Council of Turkey (TUBITAK) under Grant $1059 B 141400997$.

Declaration of interest: No conflict of interest is declared by authors.

\section{REFERENCES}

Ball, D. L., \& Bass, H. (2003). Toward a practice-based theory of mathematical knowledge for teaching. In B. Davis \& E. Simmt (Eds.), Proceedings of the 2002 Annual Meeting of the Canadian Mathematics Education Study Group (pp. 3-14). Canadian Mathematics Education Study Group.

Ball, D. L., \& Forzani, F. M. (2011). Building a common core for learning to teach: And connecting professional learning to practice. American Educator, 35(2), 17-21.

Ball, D. L., Thames, M. H., \& Phelps, G. (2008). Content knowledge for teaching: What makes it special? Journal of Teacher Education, 59(5), 389-407. https://doi.org/10.1177/0022487108324554

Barrett, J. E., \& Clements, D. H. (2003). Quantifying path length: Fourth-grade children's developing abstractions for linear measurement. Cognition and Instruction, 21(4), 475-520. https://doi.org/10.1207/s1532690xci2104_4

Baumert, J., Kunter, M., Blum, W., Brunner, M., Voss, T., Jordan, A., Klusmann, U., Krauss, S., Neubrand, M., \& Tsai, Y.-M. (2010). Teachers' mathematical knowledge, cognitive activation in the classroom, and student progress. American Education Research Journal, 47(1), 133-180. https://doi.org/10.3102/0002831209345157

Borasi, R. (1996). Reconceiving mathematics instruction: A focus on errors. Greenwood Publishing Group.

Bragg, P., \& Outhred, N. L. (2004). A measure of rulers - The importance of units in a measure. In M. J. Hoines \& A. B. Fuglestad (Eds.), Proceedings of the 28th Conference of the International Group for the Psychology of Mathematics Education (Vol. 2, pp. 159-165). Bergen University College.

Brodie, K. (2014). Learning about learner errors in professional learning communities. Educational Studies in Mathematics, 85(2), 221-239. https://doi.org/10.1007/s10649-013-9507-1

Cai, J. (2005). U.S. and Chinese teachers' knowing, evaluating, and constructing representations in mathematics instruction. Mathematical Thinking and Learning, 7(2), 135-169. https://doi.org/10.1207/s15327833mtl0702_3

Chen, J. C., Reys, B. J., \& Reys, R. E. (2009). Analysis of the learning expectations related to grade 1-8 measurement in some countries. International Journal of Science and Mathematics Education, 7(5), 1013-1031. https://doi.org/10.1007/s10763-0089148-5

Clements, D. H., \& Sarama, J. (2007). Early childhood mathematics learning. In F. K. Lester (Ed.), Second handbook of research on mathematics teaching and learning (pp. 461-555). Information Age.

Clements, D. H., \& Sarama, J. (2009). Learning trajectories in early mathematics: Sequences of acquisition and teaching. In R. S. New \& M. Cochran (Eds.), Encyclopedia of language and literacy development (pp. 1-6). Canadian Language and Literacy Research Network. http://iteracyencyclopedia.ca/pdfs/topic.php?topld=270

Clements, D. H., \& Stephan, M. (2004). Measurement in pre-K to grade 2 mathematics. In D. H. Clements, J. Sarama, \& A. M. DiBiase (Eds.), Engaging young children in mathematics: Standards for early childhood mathematics education (pp. 299-317). Erlbaum. https://doi.org/10.4324/9781410609236

Copley, J. V. (2000). The young child and mathematics. NAEYC.

Cresswell, J. W. (2012). Educational research; planning, conducting, and evaluating quantitative and qualitative research (4th Ed.). Pearson.

Cullen, C., \& Barrett, J. E. (2010). Strategy use indicative of an understanding of units of length [Paper presentation]. The 34th Annual Conference of the International Group for the Psychology of Mathematics in Education, Belo Horizonte.

Davis, B., \& Renert, M. (2013). Profound understanding of emergent mathematics: Broadening the construct of teachers' disciplinary knowledge. Educational Studies in Mathematics, 82(2), 245-265. https://doi.org/10.1007/s10649-012-9424-8

Drake, M. (2014). Learning to measure length: The problem with the school ruler. Australian Primary Mathematics Classroom, 19(3), 27-32.

Frankel, J. R., \& Wallen, N. E. (2006). How to design and evaluate research in education (6th Ed.) McGraw Hill. 
Grossman, P. L., \& McDonald, M. (2008). Back to the future: Directions for research in teaching and teacher education. American Educational Research Journal, 45(1), 184-205. https://doi.org/10.3102/0002831207312906

Grossman, T., Reyna, R., \& Shipton, S. (2011). Realizing the potential: How governors can lead effective implementation of the Common Core State Standards. NGA Center for Best Practices.

Huang, R. (2014). Prospective mathematics teachers' knowledge of algebra: A comparative study in China and the United States of America. Springer Spektrum. https://doi.org/10.1007/978-3-658-03672-0

Huang, R., \& Cai, J. (2011). Pedagogical representations to teach linear relations in Chinese and US classrooms: Parallel or hierarchical? The Journal of Mathematical Behavior, 30(2), 149-165. https://doi.org/10.1016/j.jmathb.2011.01.003

Huang, R., \& Li, Y. (2014). Promoting mathematical understanding: An examination of algebra instruction in Chinese and US classrooms. In F. K. S. Leung, K. Park, D. Holton, \& D. Clarke (Eds.), Algebra teaching around the world (pp. 213-232). Brill Sense. https://doi.org/10.1007/978-94-6209-707-0_12

Kamii, C. (2006). Measurement of length: How can we teach it better? Teaching Children Mathematics, 13(3), 154-158. https://doi.org/10.5951/TCM.13.3.0154

Kilpatrick, J., Swafford, J., \& Findell, B. (Eds.). (2001). Adding it up: Helping children learn mathematics. National Academies Press

Kloosterman, P., Rutledge, Z., \& Kenney, P. (2009). Exploring results of the NAEP: 1980s to the present: Results of the long-term trend assessment (LTT) for middle grades show positive advancement. Mathematics Teaching in the Middle School, 14(6), 357365. https://doi.org/10.5951/MTMS.14.6.0357

Knipping, C. (2003). Learning from comparing. Zentralblatt für Didaktik der Mathematik, 35(6), 282-293. https://doi.org/10.1007/ BF02656692

Lehrer, R. (2003). Developing understanding of measurement. In J. Kilpatrick, W. G. Martin, \& D. Schifter D. (Eds.), A research companion to principles and standards for school mathematics (pp. 179-192). National Council of Teachers of Mathematics.

Lehrer, R., Jaslow, L., \& Curtis, C. (2003). Developing an understanding of measurement in the early grades. In D. H. Clements \& G. Bright (Eds.), Learning and teaching measurement. 2003 Yearbook of the national council of teachers of mathematics (pp. 100121). National Council of Teachers of Mathematics.

Ma, L. (1999). Knowing and teaching elementary mathematics: Teachers' understanding of fundamental mathematics in China and the United States. Erlbaum. https://doi.org/10.4324/9781410602589

Martinez, J. G. R. (2007). Teaching mathematics in elementary and middle school. Merrill Prentice.

McGraner, K. L., VanDerHeyden, A., \& Holdheide, L. (2011). Preparation of effective teachers in mathematics. National Comprehensive Center for Teacher Quality. http://www.tqsource.org/

Ministry of National Education. (2015). Primary schools mathematics program for 1, 2, 3, and 4 grades. Devlet Kitapları Mudurlugu [State Books Directorate].

National Council of Teachers of Mathematics. (2000). Principles and standards for school mathematics. https://www.nctm.org/ standards/

National Mathematics Advisory Panel. (2008). Foundations for success: The final report of the national mathematics advisory panel. U.S. Department of Education.

Ontario Ministry of Education. (2005). The Ontario curriculum grades 1-8 mathematics. Queen's Printer. http://www.edu.gov.on.ca/eng/curriculum/elementary/math18curr.pdf

Organisation for Economic Co-operation and Development. (2005). PISA 2003 data analysis manual for SPSS users. OECD.

Outhred, L. N., \& Mitchelmore, M. C. (2000). Young children's intuitive understanding of rectangular area measurement. Journal for Research on Mathematics Education, 31(2), 144-167. https://doi.org/10.2307/749749

Rothstein, J. (2010). Teacher quality in educational production: Tracking, decay, and student achievement. Quarterly Journal of Economics, 125(1), 175-214. https://doi.org/10.1162/qjec.2010.125.1.175

Rowland, T., \& Ruthven, K. (2011). Introduction: Mathematical knowledge in teaching. In T. Rowland \& K. Ruthven (Eds.), Mathematical knowledge in teaching (pp. 1-5). Springer, Dordrecht. https://doi.org/10.1007/978-90-481-9766-8_1

Rowland, T., Huckstep, P., \& Thwaites, A. (2003). The knowledge quartet. Proceedings of the British Society for Research into Learning Mathematics, 23(3), 97-102.

Rowland, T., Huckstep, P., \& Thwaites, A. (2005). Elementary teachers' mathematics subject knowledge: The knowledge quartet and the case of Naomi. Journal of Mathematics Teacher Education, 8(3), 255-281. https://doi.org/10.1007/s10857-005-0853-5

Rowland, T., Turner, F., Thwaites, A., \& Huckstep, P. (2009). Developing primary mathematics teaching: Reflecting on practice with the knowledge quartet. SAGE. https://doi.org/10.4135/9781446279571

Sarama, J., Clements, D. H., Barrett, J. E., Cullen, C. J., Hudyma, A., \& Vanegas, Y. (2021). Length measurement in the early years: teaching and learning with learning trajectories. Mathematical Thinking and Learning, 1-24. https://doi.org/10.1080/ 10986065.2020 .1858245

Shulman, L. (1987). Knowledge and teaching: Foundations of the new reform. Harvard Educational Review, 57(1), 1-23. https://doi.org/10.17763/haer.57.1.j463w79r56455411

Shulman, L. S. (1986). Those who understand: Knowledge growth in teaching. Educational Researcher, 15(2), 4-14. https://doi.org/10.3102/0013189X015002004 
Smith, J. P., Males, L. M., Dietiker, L. C., Lee, K., \& Mosier, A. (2013). Curricular treatments of length measurement in the United States: Do they address known learning challenges? Cognition and Instruction, 31(4), $388-433$. https://doi.org/10.1080/07370008.2013.828728

Stephan, M. \& Clements, D. H. (2003). Linear and area measurement in prekindergarten to grade 2. In D. H. Clements \& G. Bright (Eds.), Learning and teaching measurement. NCTM 2003 yearbook (pp. 3-16). NCTM.

Wilson, P. S., \& Rowland, R. (1993). Teaching measurement. Research Ideas for the Classroom: Early Childhood Mathematics, 30(1), 171-194.

Zembat, I. O. (2007). Understanding the volume formula for rectangular right prisms: A different perspective. Eurasian Journal of Educational Research, 27, 205-217. 